\title{
DOCUMENTING COMPLEXITY FOR THE 20TH CENTURY HERITAGE: THE ENRICHED 3D MODELS OF THE TURIN EXPOSITION NERVI'S HALLS DIGITIZATION
}

\author{
G. Sammartano ${ }^{1,2}{ }^{*}$, G. Patrucco ${ }^{1}$, S. Perri ${ }^{1}$, R. Ceravolo ${ }^{1}$, E. Lenticchia ${ }^{1}$, A. Spanò ${ }^{1,2}$ \\ ${ }^{1}$ Politecnico di Torino. DAD, Viale Mattioli 39, 10125, Torino (Italy). DISEG, Corso Duca degli Abruzzi, 24, 10129 Torino (Italy) \\ (giulia.sammartano/giacomo.patrucco/stefano.perri/rosario.ceravolo/erica.lenticchia/antonia.spano)@polito.it \\ ${ }^{2}$ FULL - Future Urban Legacy Lab, Politecnico di Torino. Via Agostino da Montefeltro 2, 10125 Torino (Italy).
}

KEY WORDS: 3D models, $20^{\text {th }}$ century heritage, multi-temporal, reinforced concrete, metadata, structural assessment

\begin{abstract}
:
Great attention is increasingly paid to the heritage belonging to the XX century, particularly for the spatial structures made of concrete, that are a significant trait of this modern movement architecture. Since they demand today urgent conservation plans sustaining their deterioration, the multidisciplinary researches should devotes a profound investigations for tailored approaches providing a clear indication of best practices and recommendation for correct 3D documentation, information management and structural assessment and monitoring. In this framework, the Geomatics approaches are advancing the interests toward the multi-scale and multi-sensor digitization and for supporting management of complex information in enriched 3D models. The iconic halls B and C in Torino Esposizioni (Italy), designed by Pier Luigi Nervi, is the case study presented. It was recently awarded by the Getty Keeping it Modern grant. The multi-disciplinary research conducted, still in progress, focuses a particularly into the investigation of the structural analysis and consistency of ferrocement elements of the vaulted system finalized to the structural condition assessment. Here the role of multi-scale and multi-sensor 3D models is investigated, such as the development of a digital twin of the halls as a starting point to create an enriched informative system. The reconstruction of this model particularly considering the large extension and the complexity of the spaces, is addressed to works as a collector of 3D multi-sensor data and information related to the diagnostic investigation on structural health monitoring for the durability of ferrocement elements.
\end{abstract}

\section{INTRODUCTION}

In the broad panorama of techniques used for the digitisation of architectural and cultural heritage, a leading role is certainly played by studies and projects aiming at the use of $3 \mathrm{D}$ sensing methods to support structural investigations with the purpose of identifying the structural characteristics of historical buildings and determining the state of health of structures pertaining $\mathrm{CH}$. The declensions of these studies are varied, but a number of common traits can be identified.

The integration or fusion of range (TLS-Terrestrial Laser Scanning) and image-based methods (digital photogrammetry in the UAV-Unmanned Aerial Vehicle and close-range configuration), based on Structure-from-motion (SfM) techniques, has long been identified as most advantageous for the purposes of heritage digitisation (Grussenmeyer et al., 2011; Munumer \& Lerma, 2015).

In fact, in the last two decades, the use of UAV devices has proven to be extremely competitive with dense matching and reconstruction approaches (Murtiyoso \& Grussenmeyer, 2017) and performing in the framework of heritage vast structures documentation since they allow to rapidly acquire highresolution digital images and to achieve dense, accurate and relatively detailed $3 \mathrm{D}$ models and orthoimagery characterized by a high radiometric resolution (Remondino et al., 2009).

Despite that, laser scanning techniques have certainly been preferred in structural studies due to their effectiveness in reaching very high accuracy and resolution, in addition to the reliability of the 3D models and their versatility to define surfaces and structural components characterisation (Castellazzi et al., 2015; Korumaz et al., 2017). Also, they are less influenced by contextual conditions and able to combine and to compare other investigations results (Lubowiecka et al., 2009; Pieraccini et al.,
2014). A further common feature of sure interest is the general and increasingly widespread research direction connected to the use of HBIM systems to prepare 3D models capable of integrating geometric and semantic information (Brumana et al., 2017; Dore et al., 2015). Nowadays, a fundamental concept - developed with an increasing number of proposals and solutions analyses - is that the use of the HBIM strategies is not only and no longer so much oriented to solve the issues related to the 3D modeling of complex $\mathrm{CH}$ objects. This approach considers HBIM as an environment in which managing the many heterogeneous information characterizing architectural assets in connection with geometric information (Turrina \& Attico, 2021).

In a perspective that aims to increase reasoned collections of information and analyses on the $\mathrm{CH}$ focusing a standardized knowledge, (Yang et al., 2019) propose the combined use of HBIM strategies and ontological converted models with the aim to enrich semantic contents in a possible standard compliance perspective. Moreover, in the framework of the structural evaluation of complexes the simplification processes of clouds or mesh models is a crucial phase, more than in other fields, that have to be critically guided in an interdisciplinary perspective. Following a typologybased approach able to interpret the structural behaviour of the structures, the exploitation of the interoperability between parametric modeling software and those of structural analysis is a good opportunity (Abbate et al., 2020; Ottoni et al., 2017). Another very important issue concerns the massive availability of $3 \mathrm{D}$ modeling derived from heritage digitisation projects that are offered to future generations who will be engaged in conservation projects. One of the important concerns is that the quality of these modeling products is not intrinsic to the models, that is, the processes that led to obtaining them are not automatically recorded. In this sense, an EU project called VIGIE is operating, aimed at

\footnotetext{
* Corresponding author
} 
"Study on quality in 3D digitisation of tangible Cultural Heritage: mapping parameters, formats, standards, benchmarks, methodologies, and guidelines' ${ }^{1}$. The set of the aforementioned instances are the basis of the reasoning for the modeling and the enriched archiving of information both regarding the digitisation process and interdisciplinary investigations of which the paper aims to report. The Turin Exposition Centre digitisation project that will be presented in the next sections, will be the case study for evaluating whether the HBIM strategy is actually capable of constituting an archiving system in which the spatial database actually serves to represent with spatial reference the information that harmonizes data of different nature and relating to the investigations in progress.

A particularly important criticality highlighted that will be proposed is the one concerning the close connection between geometric and radiometric information that for many years has characterized the new generation of 3D models performed by reality-based techniques where metrically controlled orthophotos are usually used as textures of geometric models, and that in the parametric modeling paradigm is more than difficult.

For all these reasons, the following issues can be posed facing a complex digitisation process such as the one concerning the outdoor and indoor configuration of the Pier Luigi Nervi halls, which also provides results of parallel evaluation for their structural performances, both as regards the level of safety in static conditions and from the point of view of seismic behaviour:

- How to categorize a huge amount of data collected during systematic survey campaign and diagnostic investigation tests, considering the time of performed analyses.

Which kind of semantic structure system can be used for managing digital objects and elements, especially for interdisciplinary comparisons and exchanges

How to develop the organisation and synergic management of hybrid information coming from different knowledge areas

The aims of the digitisation project must not lose the sight of the overall framework in which this project is inserted (Section 2). In fact, the particular interest is linked to the exploration and evaluation of the role of geomatics techniques and enriched useroriented 3D models in the development of best practices and virtuous paradigms of Conservation Plans related to 20th-century buildings. In fact the preservation of the modern architecture, and particularly the concrete spatial structures (ICOMOS, 2017).

\section{TURIN EXHIBITION AND THE HALLS B AND C}

The work focuses on an exceptional heritage site, located in Torino, belonging to the $20^{\text {th }}$ century reinforced concrete legacy on the city: the halls $\mathrm{B}$ and $\mathrm{C}$, in the Turin exhibition complex. (Figure 1a) Engineer Pier Luigi Nervi conceived these outstanding structures in the years after the II World War, to host the annual Automobile Show, due to the intense and long-term activities in Torino of the FIAT motor company. The multidisciplinary approach implemented in this impressive site is related to the Keeping it Modern project - Planning Grant 2019 is promoted by the Getty Foundation, in which the research group is involved. The aims of the grants awarded is to identify projects that "have strong potential to serve as models for the conservation of other 20th-century buildings" 2 . The aim of the general research work is the development of a conservation plan (CP), through the condition assessment and diagnosis of the hall's structures, finalized to preservation, retrofit and re-use (Ceravolo et al., 2020). The colossal spatial structure made by ferrocement technique required ah hoc approach for 3D

\footnotetext{
${ }^{1}$ EU VIGIE project: https://digital-strategy.ec.europa.eu/en/funding/study quality-3d-digitisation-tangible-cultural-heritage
}

digitisation, especially for extreme accuracy in positioning 3D data co-relating inside-outside spaces. The exhibition halls digital twin is required not only to support conservation and restoration activities, but also provide metric reliability for structural and seismic assessments analyses and investigations. Moreover, today we are aware that these constructions were designed with criteria that did not consider seismic action due to the fact that they have been testing sites for techniques that at the time were still experimental. Therefore, it is a priority of the Conservation Plan to carry out a careful evaluation of the structural performances, especially for these kind of unique modern structures, leading to a higher degree of complexity when interpreting their structural behavior (Ceravolo et al., 2019; ICOMOS CHARTER, 2003; Lenticchia et al., 2021)

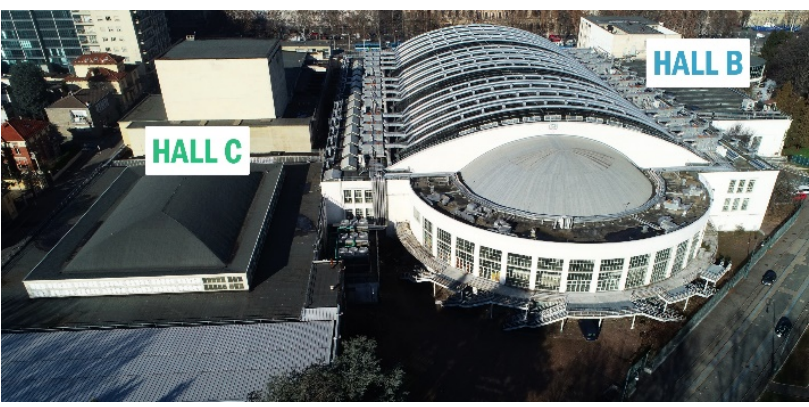

(a)

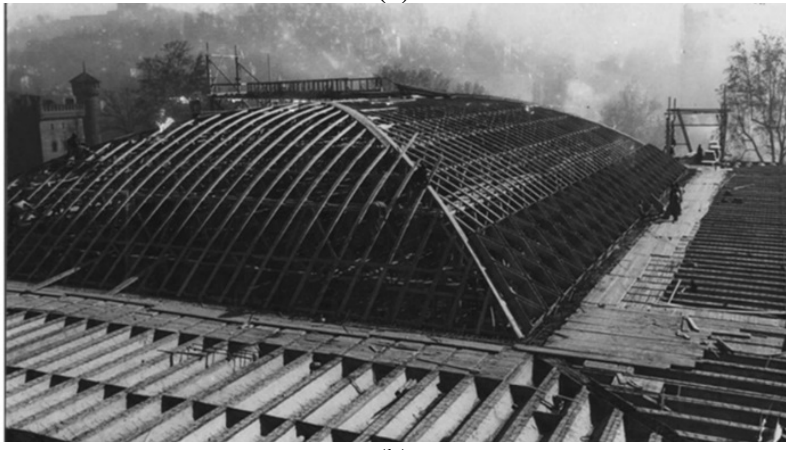

(b)

Figure 1. The Pier Luigi Nervi Halls in the Turin Exposition centre: (a) the two halls B and C from south-west UAV image; the Hall $\mathrm{C}$ during its construction site in images of the time in 1950 , the assembly of the diamond elements in ferrocement on the vault centring. $\odot$ Archivio MAXXI Roma, Fondo Nervi.

\subsection{The reinforced concrete structures}

For the construction of both the complex halls, built between 1947 and 1950, Nervi decided to employ a combination of new construction techniques and structural solutions to overcome the challenges of the client requests, the scarce amount of resources and the space to cover with a single large span roofing system. Given these premises, Nervi employed on-site precast elements combined with in-situ concrete (Figure 1b).

In fact, the prefabricated elements on-site solution speeds up the laying operations and saves the quantity of material used.

The designer decided to use for the first time in a large-scale building his patent: the ferrocement, with a maximum thickness of 4-5 centimetres, also allowing for greater ease of installation. One of the main advantages of the use of the ferrocement, in addition to its great malleability and flexibility, is its greater lightness with respect to reinforced concrete.

\footnotetext{
${ }^{2}$ Getty Foundation, Keeping It Modern projects:

https://www.getty.edu/foundation/initiatives/current/keeping it modern/
} 
Besides, the extensive presence of glass material surfaces alongside ferrocement texture has contributed to adding variables on the organization and adaptability of the sensors approach to the building digitization.

\section{RESEARCH FRAMEWORK AND OBJECTIVES}

Recently, large and complex documentation contexts are interdisciplinary challenges and they prove to be workout for experimentation and testing of advanced methodology for data recording, modeling and management. Interdisciplinarity represent a huge added value in the framework of the documentation of modern architecture buildings since a very high number of researchers operating in different disciplines, such as surveyors, structural engineers, restorers, historians, physicists. (Bitelli et al., 2017; Tucci et al., 2017). For this reason, it is crucial to synergistically manage all the contributions to the knowledge with accuracy and awareness.

The presented research, as introduced, operates in the direction of managing hybrid data and knowledge supporting the activities of the Conservation Plan of the Nervi's halls, with the aim of creating a digital twin in the form of a 3D digital platform. Therefore, the 3D model is called firstly to twin the geometric and radiometric content, the structural elements and their material characterisation, critically exploring the modeling solution and the HBIM management paradigm. In these terms, it is expected to host and to manage the collection, cataloguing and categorisation of diagnosis and experimental tests on structural assessment.

The main goal, in general terms, is the accurately spatial correlation of the collected data, whose methods are presented in Section 4 , and declined specifically in 3 tasks:

1. The definition of the global configuration of the building envelope of the spatial structure, focusing the thickness of the ferrocement elements and studying the intradosextrados issue (Section 4.1);

2. The recognition, segmentation and modeling of the elements involved in the structural analysis (Section 4.2);

3. The organisation and storage of the multi-disciplinary diagnostic investigation tests datasets oriented to generate their spatial relation in the 3D HBIM model (Section 4.3).

The huge remarkable structure required first of all a multi-sensor and multi-scale approach of documentation of the ferrocement elements structure, that was conducted by progressive survey campaign concerning the accurate management of outdoorindoor spaces of the halls. The campaigns activity is still in progress. The methodological research validating the generation of the fusion-based enriched model is being conducted with the aim of balancing the density of information along the scale and specific structural element, and proper level of details as well.

\section{METHODS AND STRATEGIES}

The multi-sensor approach is organized according to the use of different range- and image-based techniques in order to generate a multi-scale 3D model. The use of UAV photogrammetric approach was conceived for the documentation of the articulated complex in the outdoor spaces and extrados surface of roofing and vaults, and for the relation with the urban context. In indoor environments, the hierarchy of documentation goals requires use of different range-based techniques according to complexity issues. Static LiDAR used for the main halls structural elements was flanked by Mobile Mapping System by SLAM-based portable technologies in case of non straightforward accessibility of enclosed spaces, galleries and underground rooms. Indoor data acquisition and modeling also requires the integration of highscale digitization with the use of a close-range photogrammetric approach for both geometric and radiometric information. The use of DSLR cameras and micro-drones for great heights are conceived too.
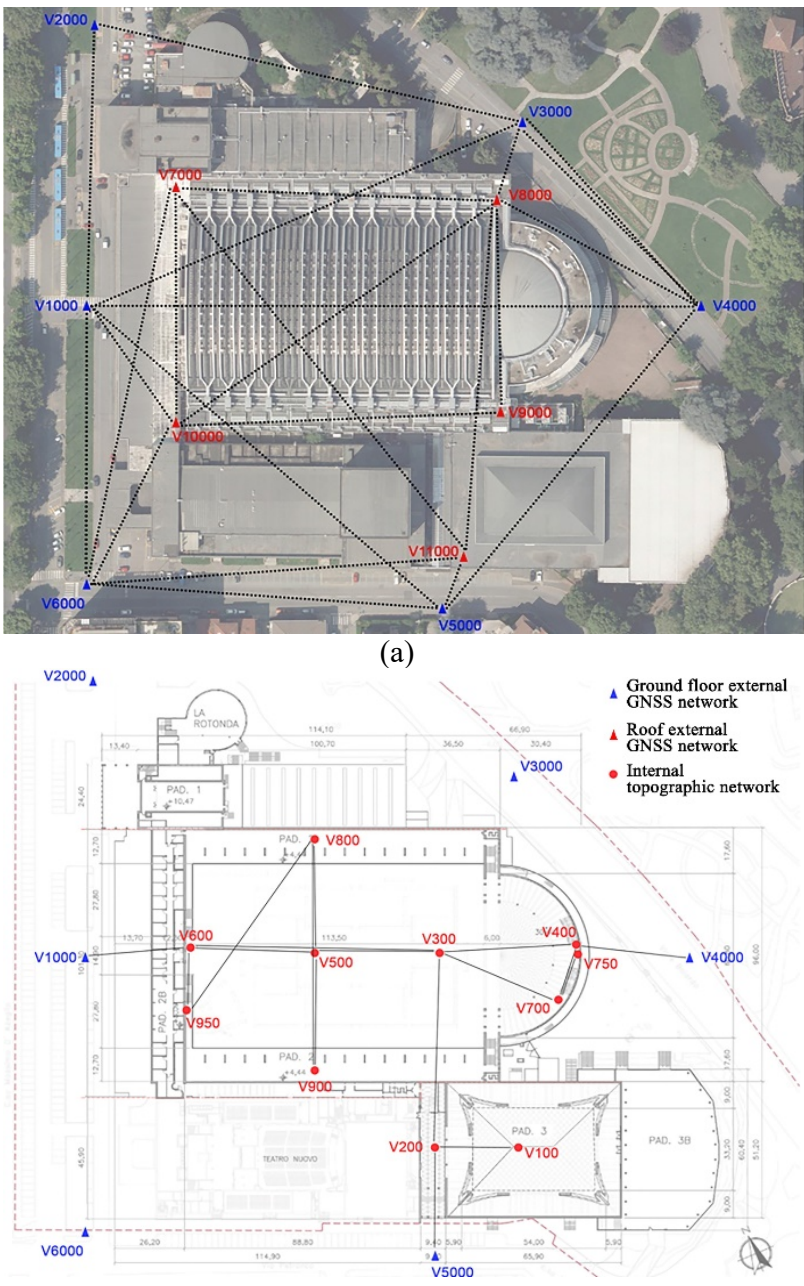

(b)

Figure 2. The topographic network and vertices distribution

The establishment of a common reference system by topographic approach, characterized by a verifiable accuracy, represents in many cases the crucial starting point for most of the procedures that involve the co-registration and the integration of heterogeneous data derived from different sensors and techniques. Particularly for this site objects, the correlation of indoor and outdoor data was crucial for the metric requirements related to the ferrocement elements description.

All the measures acquired in the framework of the Torino Esposizioni survey campaigns have been georeferenced starting from the topographic network, and the WGS84/UTM 32N world reference system was used in the measures settings.

The overall hierarchical organization of indoor-outdoor and floors levels data and metric control for errors propagation in the measures of the 3D documentation have been guarantee by the measurement of a topographic control network.

The adjustment of the network delivered a millimetre-level accuracy, and the final configuration distributed 11 outside vertices ( 6 at the ground level and 5 on the rooftops) and 11 internal vertices (Figure 2). The external vertices of the topographical network, as concerns the outdoor areas and the roof, are measured using Global Navigation Satellite System (GNSS) and establishing the absolute position. 
In the hierarchical organisation of measures controlling the error propagation, the topographic measures by Total Stating (TS) were favoured over the use of RTK GNSS for the necessary distribution of Ground Control Points (GCPs) and Check Points (CPs) for the UAV photogrammetric processing.

The TS technique was used also for indoor network and for the internal topographic survey of GCPs and CPs distribution, both for scans co-registration and photogrammetric blocks orientation, as well as the measurements and positioning of diagnostic tests.

\subsection{The envelope documentation by UAV photogrammetry for extrados-intrados modeling}

Since one of the main aims of the 3D metric survey operations carried out in the project framework is the achievement of a correct morphological characterisation of the exceptional vaulted system characterizing the building, the measurement and definition of the envelope (extrados-intrados) of the spatial structure is the first task to be achieved.

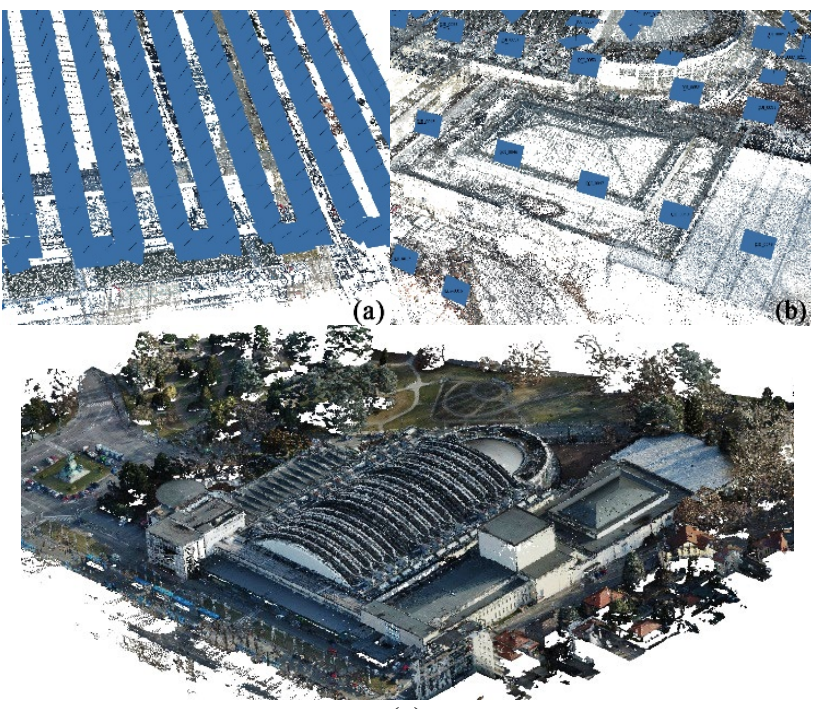

(c)

Figure 3. The photogrammetric project: (a) Example of nadir acquisitions (b) $45^{\circ}$ oblique images; (c) the 3D dense cloud.

For this goal, the UAV photogrammetric data for external spaces and the static LiDAR (Section 4.2) in indoor vaulted spaces have been accurately co-registered. The UAV photogrammetric acquisition has been planned in order to properly document the roofing systems of halls B and C and the external areas. During the survey campaign, the aerial images have been collected using a DJI Phantom 4 equipped with a high-resolution camera (1', CMOS sensor, 20 Megapixels; $24 \mathrm{~mm}-35 \mathrm{~mm}$ equivalent lens; $4864 \times 3648 \mathrm{px}$ image resolution). A consolidated marker-based approach has been followed for bundle block adjustment (BBA). The points were homogeneously distributed on all the surveyed surfaces to guarantee the possibility to perform the georeferencing and the accuracy control on the data during the photogrammetric processing. Due to the extremely large dimensions of the building, a set of both markers and natural points has been measured favouring the use of the total station with the aim to enhance the accuracy of BBA ( $n^{\circ} 30$ GCPs and $\mathrm{n}^{\circ} 10 \mathrm{CPs}$ ). Different photogrammetric flights have been planned to acquire the higher number of roofing surfaces of the Nervi complex, and both nadir and oblique $\left(45^{\circ}\right)$ acquisitions have been integrated to cover both horizontal (the rooftops) and vertical surfaces (external façades) Figure 3.

The flights have been planned from an average shooting distance of 60 meters height with an estimated mean GSD (Ground
Sample Distance) of $1.6 \mathrm{~cm}$. During the different flights, almost 1900 images have been collected (850 nadir and 1072 oblique images). The images block has been processed following a Structure-from-Motion (SfM) based traditional pipeline to achieve a dense point model.

\subsection{Static LiDAR for structural elements numerical modeling}

A second essential task is dedicated to the architectural elements scale, focusing on the importance of identifying and modeling the structural components, supporting the numerical FEM modeling finalized to structural analysis Figure 4. The treatment of the LiDAR data will have to meet these prerequisites in order to support a numerical modeling based on the as-built state and not only on a model based on the original documentation drawings. It is now important a reflection on the modeling solution of these elements, guiding them the geometric scan-to-BIM modeling of NURBS components of hall C.

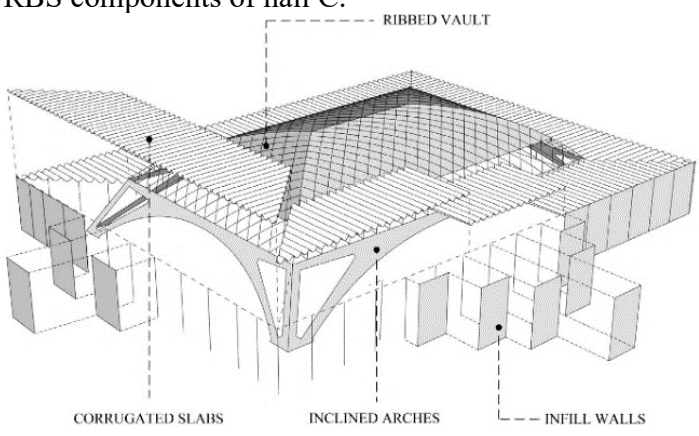

Figure 4. The structural elements indication in hall C.

The large vault of the Hall rests on four arches with a plane inclined according to the resultant of the thrust of the vault and the weight of the perimetral corrugated slab. The latter, built of prefabricated elements in ferrocement, constitutes an important load-bearing element of the vault itself. In fact, the horizontal rigidity of the slab, was conceived to redistribute and balance the thrust of the vault (Lenticchia et al., 2017). In order to bring evidence of this redistribution effect, Nervi assumed for the undulated slabs a rectangular frame model embracing the vault. The hall is then completed by a series of slim pillars and infill walls, which sustain the corrugated slabs.

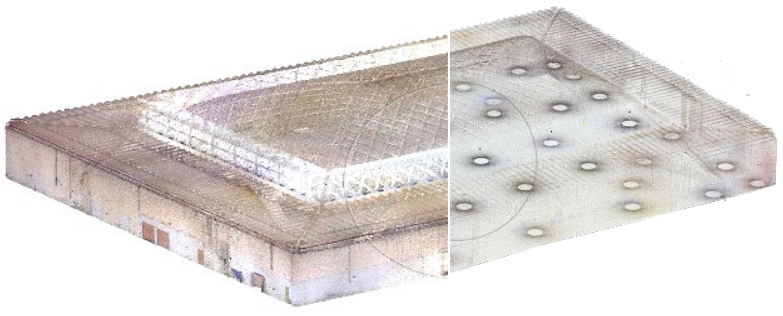

(a)

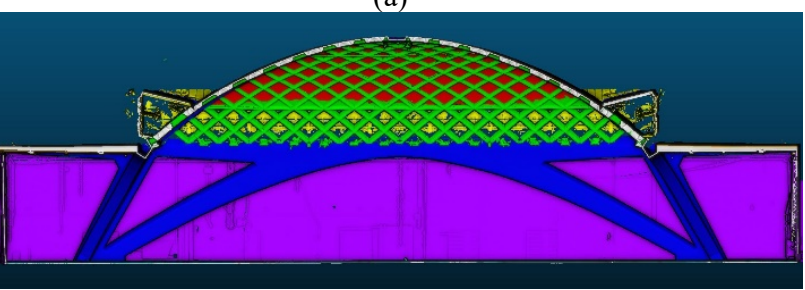

(b)

Figure 5. The static LiDAR point cloud: (a) the complete point cloud with indication of scan positions; (b) the optimized and segmented point cloud referring to the structural elements. 
The ribs of the vault and the ring beam can be considered and modeled as mono-dimensional elements, whereas the ferrocement filling slabs of the vault and the corrugated elements can be modeled with bi-dimensional elements. On the contrary, the arches should be modeled as solid elements since their monolithic nature indicates that one dimension is not negligible compared to the others, and it is necessary to interpret their three-dimensional stress state. Moreover, arches present variable sections, and modeling the mas solids elements allows to not incur in oversimplifications.

For this reason, a complete laser scanning survey has been carried out using two phase shift laser scanning systems from Faro: Faro Focus $^{3 \mathrm{D}}$ X 330 and Faro Focus ${ }^{3 \mathrm{D}} \mathrm{S} 120$ (specifications respectively for X 330/S120: Field of view - Hz and V: 305/360 ${ }^{\circ}$; Accuracy \pm 2 mm@10 m; Acquisition speed: up to 976.000 pt/s

Camera RGB). $\mathrm{N}^{\circ} 44$ scans have been acquired, as shown in Figure $5 \mathrm{a}$. The high number of collected point clouds is dependent on the very large dimensions of the surveyed halls and due to the presence of a high number of recesses in the vaulted elements. In order to ensure the correct overlapping and homogeneity of points distributions and avoiding presence of occlusions and lack of data, the acquisition geometry has been carefully planned. The laser scanner point clouds have been registered following a two-steps procedure. Firstly, a cloud-to-cloud registration based on a ICP (Iterative Closest Point) algorithm has been performed, exploiting the high overlapping existing between the different scans and the geometric features of the room. Then the block of scans has been rigidly roto-translated in the correct reference system using a set of 40 points (measured with a total station). Both checkboard targets affixed to the walls and on the basement of the pillars have been measured in the lower part of the hall), as well as natural points on the upper areas of the pavilion and on the vault (unreachable by the operator). In this case the markers have been also used as CP to evaluate the metric accuracy. The metric accuracy has been evaluated after the ICP-based procedure and also on the markers used as control points.

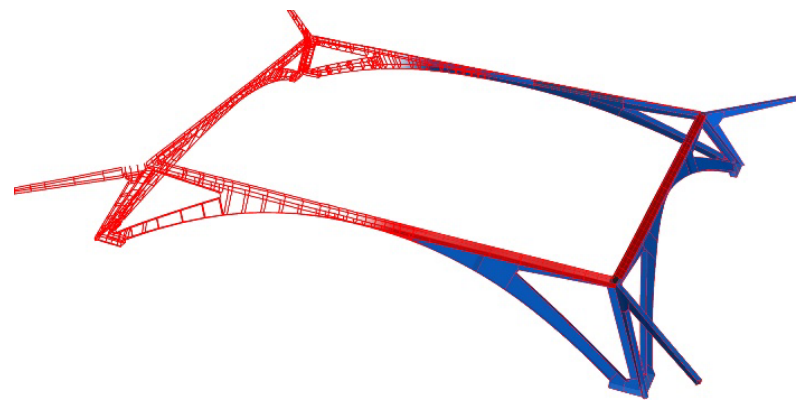

(a)

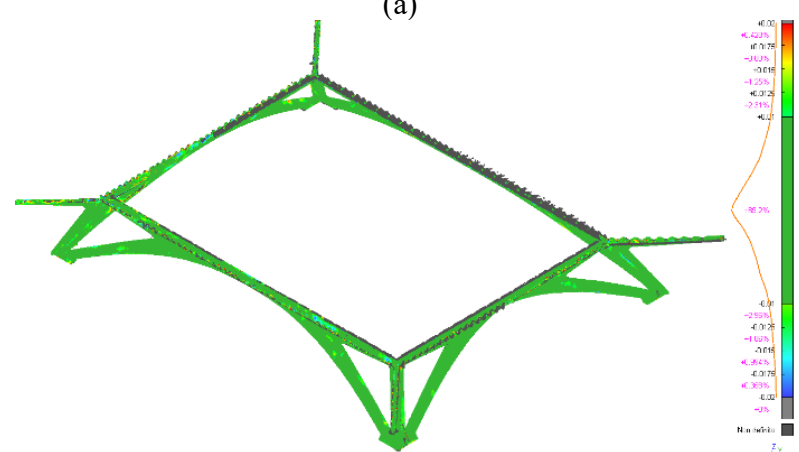

(b)

Figure 6. The modeling procedure: (a) from the point cloud, to mesh, NURBS objects; (b) deviation analysis between the original point cloud and NURBS model. $90 \%$ of the points with discrepancy lower than $1 \mathrm{~cm}$.
The quality results are: $2 \mathrm{~mm}$ for ICP registration and $7 \mathrm{~mm}$ in target-based registration. Considering the very high spatial resolution of the final point cloud, derived by the 44 acquired scans after a process of noise filtering, redundant points elimination and RGB values optimisation, the dense model derived from laser scanning technologies has been used as primary data for the subsequent elements segmentation (Figure 5a) and 3D NURBS modeling operations (Figure 6a), which have been carried out in the Rhinoceros platform.

Starting from a high-resolution polygonal mesh generated from each of the segmented point clouds, a NURBS modeling has been performed with the aim to optimise the $3 \mathrm{D}$ model without degrading the metric accuracy. A sequence of sections has been extracted allowing the reconstruction of the principal lines of the object aimed at the modeling of the structural elements simplified geometries Figure 6a. During the modeling phase multiple deviation analyses have been performed, to verify that the discrepancies between the NURBS surfaces and the original LiDAR point cloud were minimal. As it is possible to observe the performed distances analyses in Figure 6b, approximately the discrepancies between the $90 \%$ of the points of the reality-based original data and the modelled surfaces are lower than $1 \mathrm{~cm}$.

\subsection{Very-high-scale photogrammetric documentation for multi-temporal enrichment of diagnostic investigation}

One of the three main aims of this project, as introduced, is represented by the opportunity to document the different phases of the multiple investigation and knowledge processes and therefore to properly structure the information connected to the documentation phases. Consequently, it is mandatory a constant and accurate monitoring and co-registration of data also in a hierarchical multi-scale perspective.

Great importance was paid to the inclined arches of the structure. The most important load bearing elements are, in fact, the inclined arches elements and their basements. During the documentation phase it emerged that Nervi decided to build these elements by casting different typology of concrete (Figure 7a). In fact, the portion of the arch as well as the upper part were built with a concrete called "680 type", which for the time was a high resistance concrete. While the strut was built by casting a medium- resistance concrete called "500 type". Concrete was produced by the same cement factory: the Unione Cementi Marchino. The mechanical testing campaign has been designed accordingly to verify the correspondence of the material with the actual structure. Moreover, the different pouring stages are also reflected in some cracks identified on the arches. As shown in (Figure $7 \mathrm{~b}$ ), some cracks were detected at the base of all arches during the surveying and testing campaign. Some cracks are clearly related to the different pouring stages, while other cracks are of a physiological nature and can be attributed to agent coactions, including corrosion and capillary rise of water and humidity.

To respond to this need, the very high-scale survey should satisfy the documentation of geometric and radiometric consistency before and after the diagnostic investigations conducted by the Structural Engineering team on the basement of inclined arches. These consisted in:

- Position of coring and exposed irons

- Position of the sensors used during sonic diagnostic investigations

- Location of cracks 


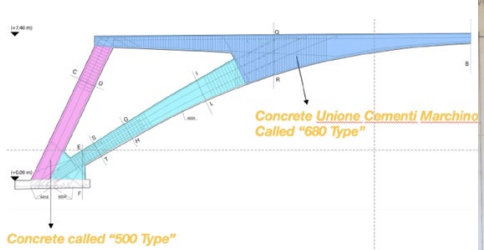

(a)

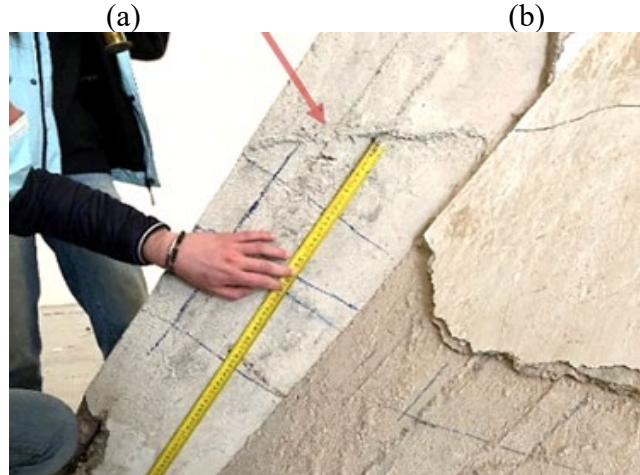

(c)

Figure 7. The analysis focused on the basements elements of the inclined arches: (a) different pouring stages and (b) casting of different concrete typology in the Nervi's design document; (c) cracks detected at the base of all arches.

In these specific occasions of interdisciplinary work, an integration of a very-high-scale close-range photogrammetric survey approach was conducted, focusing on the basements of the four pillars in the pavilion $\mathrm{C}$. This has been useful for the location of the progressive diagnostic investigation points on the 3D multi-temporal model Figure 8.

In fact, it has been considered the most appropriate approach for the rapidity of the acquisitions (the survey of each pillar required approximately 30 minutes) and for the possibility to achieve a metric product characterized by a high-resolution geometric and radiometric content (to provide the information connected to the consistency and the material of the ferrocement pillars). A highresolution Digital Single Lens Reflex camera has been used (Canon EOS 5DSR) equipped with a $25 \mathrm{~mm}$ Zeiss lens and 8085 overlapping images ( for each basement.

A homogeneous illumination was necessary to properly achieve a complete and effective radiometric digitisation, in terms of consistency and characteristics of the materials, and here two led panels have been used to artificially enlighten the basements during the shooting phase, due to the bad lighting conditions inside the hall.

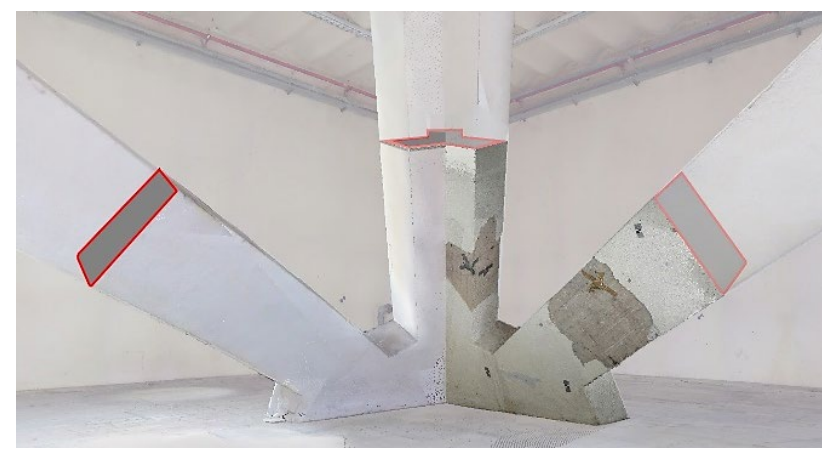

Figure 8. Multi-temporal photogrammetric data on different times.

\section{RESULTS AND DISCUSSION}

The integrated approach proposed in this research starts from the assumption that the 3D multi-scale and multi sensor model plays a crucial role in the multiple investigations on the structural assessment of this complex ferrocements architecture of XX century, and its effectiveness is supporting structural analysis based on the achievement of the following goals, in inverse order here reported. The project developments of the following stages take advantage of many reflections here reported.

The importance of implementing a rapid high-scale strategy based on the integration of LiDAR, photogrammetric approach and topographic measures for the multi-temporal documentation of diagnostic investigation tests is evident in the creation of the multi-scale digital twin of the structure. The 3D data and points are organized in NURBS and they can be stored in their spatial relation with the 3D model generated with the as-build approach by the HBIM paradigm. Its important meaning, however, must not be reduced to modeling scope only, but it is necessary to explore the potential of the management of metric and radiometric information, for which the BIM space still has bottlenecks. (Section 4.3)

The optimization of a great amount of high-scale LiDAR scans for the 3D modeling of structural elements according to the hierarchy of the spatial structure defined by Nervi's conception. (Section 4.2)

These 3D modeling procedures represent the next step, which will consist in the creation of a database of different kinds of information able to accomplish different purposes: on one side, to support 3D finite-element analyses deepening the knowledge of the architectural elements which have been acquired and modelled; on the other side to serve as a repository of information connected not only to the architectural object, but also to the other different aspects also including those related to the knowledge processes. Starting from the high-scale photogrammetric model (Figure 8), a NURBS model has been generated, with the aim to represent not only the geometric features of the investigated basement, but also mapping the different analyses which have been carried out during the documentation campaign Figure 9.

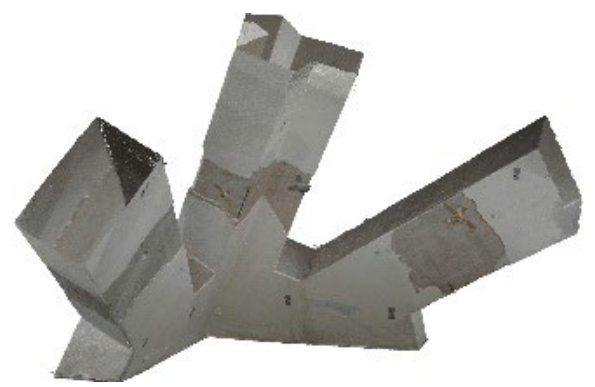

(a)

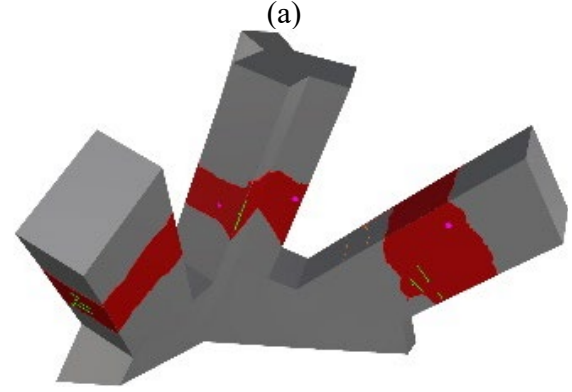

(b)

Figure 9. (a) Photogrammetric model of the basement; (b) Mesh-to-NURBS models and objects related to diagnostic investigations. 
In this complex framework of interdisciplinary research, the definition of the global geometric configuration of the structural elements building is a crucial mission and particularly the study of the envelope issues of the spatial thin ferrocement structure. In fact, the high-accuracy integrated 3D model is able to retrieve the consistency of the ferrocement envelope element experimentally designed by Nervi, and defining with accurate reality-based data, the specific intrados-extrados thickness (Section 4.1)

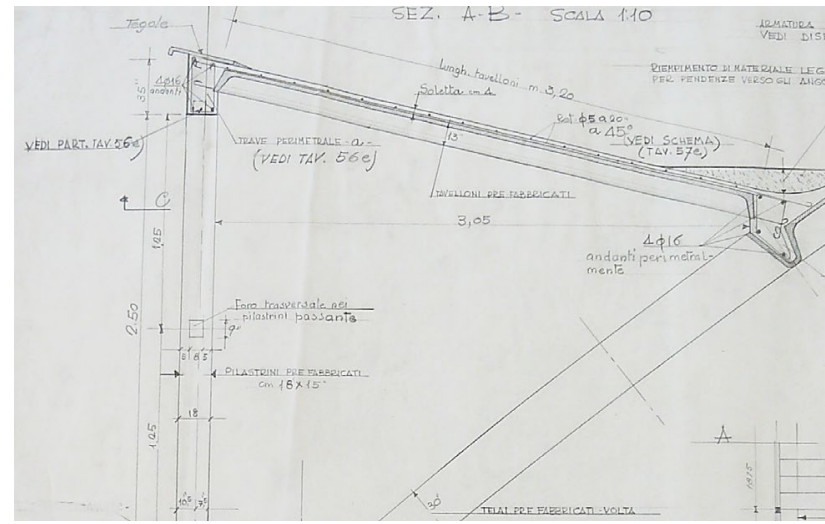

Figure 10. Historical drawings for hall C: the constructive detail of the perimeter skylights, from CSAC Archive, Parma.

In fact, the Nervi proposal was to push the ferrocement thickness to minimum limits largely documented in archival drawings Figure 10, that is expected about $5 \mathrm{~cm}$, to which it is necessary to truly consider $2 \mathrm{~cm}$ of waterproof sheath in addition. Therefore, it was decided to verify this correspondence between the design phase and the reality of measuring it in twelve distributed points on the shell according to Figure 11. The measurement of the distance between two clouds is not a well-defined and easy operation, since the multiscale approach provides cloud types that are different in density and noise. Particularly the noise error due to the presence of the glass increases the uncertainty of the empiric evaluation. For this reason, redundant measurements were addressed and applied to a transversal section profile with the aim to derive even the statistical quality parameters. It has been derived a value of $7.4 \mathrm{~cm}$ as the mean measure of the thickness among the twelve, and a s value of $1.2 \mathrm{~cm}$, which are values that are perfectly coherent with the Nervi project drawings Figure 10. Since this thickness is not directly verifiable, a thickness check near an opening was performed (with a correspondence of $1 \mathrm{~cm}$ residual between measurement on integrated clouds and direct measurement on the object). Figure $11 \mathrm{~b}$ and $\mathrm{c}$.
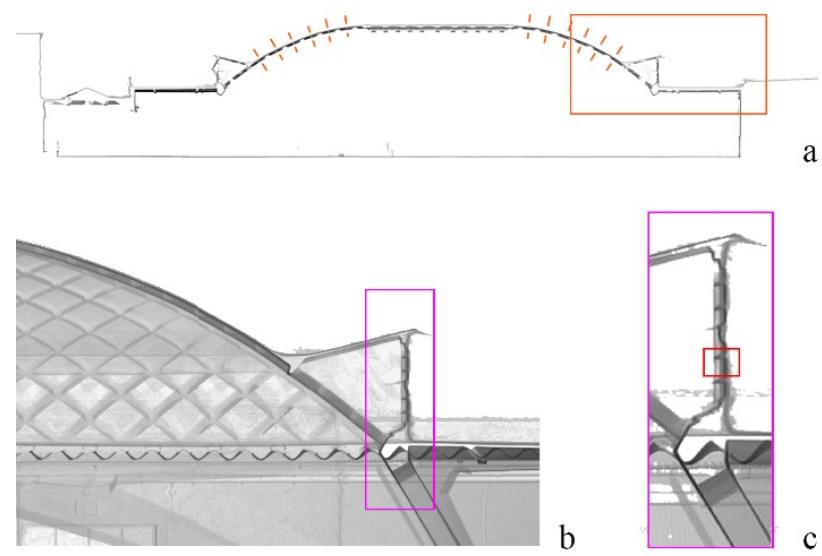

Figure 11. Longitudinal section of the integrated 3D model

(LiDAR+UAV) (a), with a zoomed view (b) of the vaulted system node and the perimeter skylights (b).

The purposes at the basis of the fusion-based 3D model of the structure envelope are conducted also in order to appreciate deformations that typically took place and progressed in the structures history and the settling of this very thin elements due to free-span, the materials behaviour and its own weight, the socalled flouage. The static analysis carried out, in a first step, on the numerical model based on the original documentation (drawings and calculations) returns that the max displacement is expected at the midpoint of the internal frame (Figure 12).

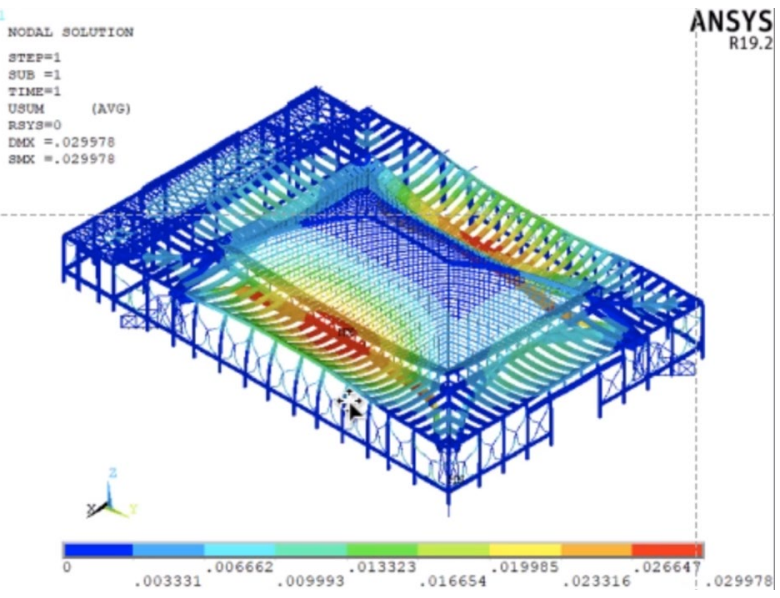

Figure 12. The static analysis on the numerical model based on the original documentation, with indication of max displacement (red).

This deformation is reflected on the actual structure, where it can be seen by the view from the top water accumulation in correspondence with the maximum deformation level of the slabs. The visualisation of the DSM in colour ramp, classified in centimetric classes, allows us to appreciate this phenomenon under investigation from a structural point of view (Figure 13).

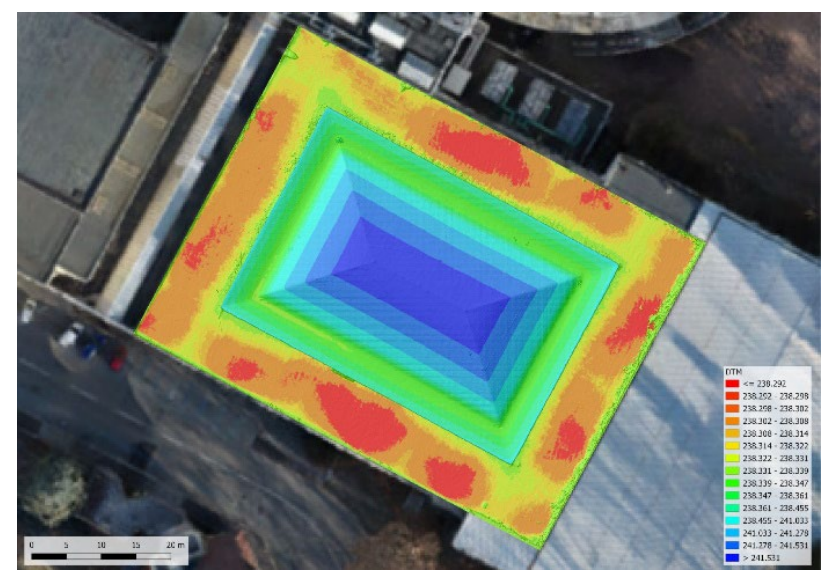

Figure 13. The UAV photogrammetric DSM superimposed to orthophoto, with range scale colour enlightening the flouage deformation areas on the extrados of the corrugated slabs.

\section{CONCLUSION AND FUTURE PERSPECTIVES}

The presented research, inserted in the framework of the Getty Keeping it Modern project, aims to support the conservation plan and the preservation projects that "have strong potential to serve as models for the conservation of other 20th-century buildings." The activities on Torino Esposizioni halls want to propose virtuous models and recommendations for conservation plans, that besides are not so diffused for XX century concrete modern architecture. The integrated experimental activities are supposed to deliver contribute to a new approach to diagnosis and 
evaluation of ferrocement structures, that considers allencompassing behavior and the vulnerabilities of heritage structures.

The study proposes a first experiment on the generation of digital 3D models as multidisciplinary databases, based on a multisensor approach and using multi-purpose data merging on the 3D model itself. Moreover, it is possible to conceive a strategy for multi-temporal investigations on $3 \mathrm{D}$ models. The research perspectives are defined in the direction of boosting the role of geomatics 3D enriched models capable to twin the consistency and complexity of heritage objects and manage them in supporting the structural assessment and the conservation plans. The digital twins 3D model, generated by accurate geometric survey through LiDAR and 3D imaging restitution, could be able to collect, represent, organize and manage the measurements and spatial correlation of construction defects, deterioration, irregularities, the damage caused by previous transformation and structural events. The data models of the digital twin are able to achieve the capacity of organizing and relating experimental tests on the building and its materials, the dynamic vibration-based tests. In this scenario the evaluation of HBIM solution for management of multi-temporal data is crucial. In a multi-scale perspective, it is interesting also to investigate the focus on 3D high-scale modeling on mock-ups related particularly to specific ferrocement elements as the inclined arches and wave ashlar.

\section{ACKNOWLEDGEMENTS}

The present work is supported by the Keeping it Modern grant awarded by The Getty Foundation of Los Angeles (USA). The authors would also like to acknowledge the City of Turin, owner of the buildings and active partner of the project, and Società Committenza Piemonte (SCR).

\section{REFERENCES}

Abbate, E., Invernizzi, S., \& Spanò, A. (2020). HBIM parametric modelling from clouds to perform structural analyses based on finite elements: a case study on a parabolic concrete vault. Applied Geomatics, 1-18. https://doi.org/10.1007/s12518-020-00341-4

Bitelli, G., Balletti, C., Brumana, R., Barazzetti, L., D’Urso, M. G., Rinaudo, F., \& Tucci, G. (2017). Metric documentation of Cultural Heritage: research directions from the italian GAMHER project. ISPRS - International Archives of the Photogrammetry, Remote Sensing and Spatial Information Sciences, XLII-2/W5, 83-90.

Brumana, R., Della Torre, S., Oreni, D., Previtali, M., Cantini, L., Barazzetti, L., Franchi, A., \& Banfi, F. (2017). HBIM challenge among the paradigm of complexity, tools and preservation: the basilica di Collemaggio 8 years after the earthquake (L'Aquila). ISPRS International Archives of the Photogrammetry, Remote Sensing and Spatial Information Sciences, XLII-2/W5, 97-104.

Castellazzi, G., D’Altri, A. M., Bitelli, G., Selvaggi, I., \& Lambertini, A. (2015). From Laser Scanning to Finite Element Analysis of Complex Buildings by Using a Semi-Automatic Procedure. Sensors, 15(8), 18360 18380 .

Ceravolo, R., de Lucia, G., Lenticchia, E., \& Miraglia, G. (2019). Seismic structural health monitoring of cultural heritage structures. In Springer Tracts in Civil Engineering (pp. 51-85). Springer.

Ceravolo, R., de Lucia, G., Lenticchia, E., Miraglia, G., Quattrone, A., Tondolo, F., Matta, E., Sammartano, G., Chiorino, C., Bruschi, G., Faccio, P., \& Nanni, A. (2020). Challenges in the reuse and upgrade of Pier Luigi Nervi's structures. In L. P. and C. M. (Eds. . P. Roca (Ed.), SAHC 2020 - 12th International Conference on Structural Analysis of Historical Constructions.

Dore, C., Murphy, M., McCarthy, S., Brechin, F., Casidy, C., \& Dirix, E. (2015). Structural simulations and conservation analysis-historic building information model (HBIM). International Archives of the
Photogrammetry, Remote Sensing and Spatial Information Sciences ISPRS Archives, 40(5W4), 351-357.

Eisenbeiß, H. (2009). UAV Photogrammetry [ETH Zurich - Institute of Geodesy and Photogrammetry]. http://citeseerx.ist.psu.edu/viewdoc/download?doi=10.1.1.461.3781\&re $\mathrm{p}=\mathrm{rep} 1 \&$ type $=\mathrm{pdf}$

Grussenmeyer, P., Alby, E., Assali, P., Poitevin, V., Hullo, J.-F., \& Smigiel, E. (2011). Accurate documentation in cultural heritage by merging TLS and high-resolution photogrammetric data. In F. Remondino \& M. R. Shortis (Eds.), Videometrics, Range Imaging, and Applications XI (Vol. 8085, Issue 21, p. 808508). SPIE.

ICOMOS. (2017). ISC20C, Approaches to the conservation of Twentieth-century cultural heritage Madrid - New Delhi Document. http://www.icomos-isc20c.org/madrid-document/

ICOMOS CHARTER. (2003). ICOMOS charter-principles for the analysis, conservation and structural restoration of architectural heritage (2003).

Korumaz, M., Betti, M., Conti, A., Tucci, G., Bartoli, G., Bonora, V., \& Fiorini, L. (2017). An integrated Terrestrial Laser Scanner (TLS), Deviation Analysis (DA) and Finite Element ( FE ) approach for health assessment of historical structures . A minaret case study. 153(July), 224238 .

Lenticchia, E., Ceravolo, R., \& Chiorino, C. (2017). Damage scenariodriven strategies for the seismic monitoring of XX century spatial structures with application to Pier Luigi Nervi's Turin Exhibition Centre. Engineering Structures, 137, 256-267. https://doi.org/10.1016/j.engstruct.2017.01.067

Lubowiecka, I., Armesto, J., Arias, P., \& Lorenzo, H. (2009). Historic bridge modelling using laser scanning, ground penetrating radar and finite element methods in the context of structural dynamics. Engineering Structures, 31(11), 2667-2676.

Munumer, E., \& Lerma, J. L. (2015). Fusion of 3D data from different image-based and range-based sources for efficient heritage recording. 2015 Digital Heritage, 83-86.

Murtiyoso, A., \& Grussenmeyer, P. (2017). Documentation of heritage buildings using close-range UAV images: dense matching issues, comparison and case studies. The Photogrammetric Record, 32(159), 206-229. https://doi.org/10.1111/phor.12197

Ottoni, F., Freddi, F., \& Zerbi, A. (2017). From "models" to "reality", and return. Some reflections on the interaction between survey and interpretative methods for built heritage conservation. ISPRS International Archives of the Photogrammetry, Remote Sensing and Spatial Information Sciences, XLII-5/W1, 457-465.

Pieraccini, M., Dei, D., Betti, M., Bartoli, G., Tucci, G., \& Guardini, N. (2014). Dynamic identification of historic masonry towers through an expeditious and no-contact approach: Application to the "Torre del Mangia" in Siena (Italy). Journal of Cultural Heritage, 15(3), 275-282.

Remondino, F., Girardi, S., Rizzi, A., \& Gonzo, L. (2009). 3D modeling of complex and detailed cultural heritage using multi-resolution data. Journal on Computing and Cultural Heritage, 2(1), 1-20.

Tucci, G., Bonora, V., Conti, A., \& Fiorini, L. (2017). Digital Workflow for the Acquisition and Elaboration of 3D Data in a Monumental Complex: the Fortress of Saint John the Baptist in Florence. ISPRS International Archives of the Photogrammetry, Remote Sensing and Spatial Information Sciences, XLII-2/W5(September), 679-686.

Turrina, A., \& Attico, D. (2021). The reconstruction of a dynamic inventory model toward shared HBIM libraries for vaulted systems. Proceedings of the ARQUEOLÓGICA 2.0 8th International Congress on Archaeology, Computer Graphics, Cultural Heritage and Innovation.

Yang, X., Lu, Y.-C., Murtiyoso, A., Koehl, M., \& Grussenmeyer, P. (2019). HBIM Modeling from the Surface Mesh and Its Extended Capability of Knowledge Representation. ISPRS International Journal of Geo-Information, 8(7), 301. 